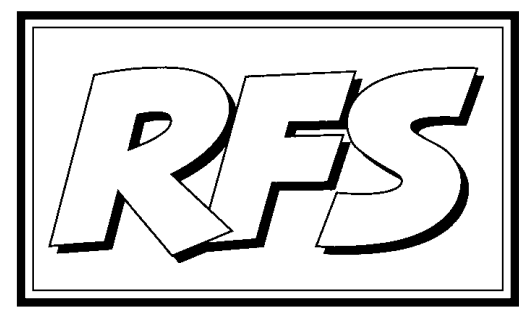

Revista de Fomento Social, 55 (2000), 419-433

\title{
Mecanismos de justificación de la violencia y cultura de paz
}

\section{J esús María ALEMANY BRIZ*}

Naciones Unidas, enfrentada al desafío de forjar el futuro en el próximo milenio, ha declarado el 2000 Año Internacional de la Cultura de Paz (A/RES52) 15). El entonces Director General de la UNESCO, Federico Mayor Zaragoza, ha invitado con esta ocasión a decir ibasta ya!: Arranquemos a la turbulenta historia de este siglo una nueva esperanza y dejemos que la rebeldía no violenta, la indocilidad creativa, la insumisión de quienes no se resignan a admitir lo inadmisible, hagan posible la transición al diálogo y a la tolerancia para transformar la cultura de guerra y de violencia en una cultura de paz y conciliación (El Correo de la Unesco, enero 1999, p. 9).

\section{1. ¿ES POSIBLE UNA CULTURA DE PAZ EN UN MUNDO DE VIOLENCIA?}

No es necesario esforzarse en demostrar que existe la violencia a gran escala en nuestro planeta. Se asoma continuamente a la pantalla de nuestros informativos y se hace presente en nuestras calles. Nunca las guerras se han

* J esuita. Director del Seminario de Investigación para la Paz de Zaragoza. 
cobrado tantas vidas civiles como ahora, llegando a constituir el $90 \%$ de todas sus víctimas. La brutalidad de los enfrentamientos en todos los continentes sólo es pareja a la proliferación creciente de las armas y al odio de los corazones. Genocidios por motivos étnicos, nacionalistas o religiosos son la paradoja de la globalización de la economía. Ejércitos, guerrillas, grupos paramilitares, terroristas, protagonizan acciones cuyo común denominador es la muerte y el miedo. Los atentados, secuestros, torturas y asesinatos siguen enlutando las familias y tienen como víctimas intencionadas a niños y mujeres. Los derechos humanos e incluso el derecho humanitario de guerra brillan por su ausencia normalmente en estos conflictos.

En estas circunstancias, por más que Naciones Unidas lo proclame, ¿es posible hablar de una cultura de paz o de una educación para la paz? Esta pregunta surge no como producto de una elucubración intelectual, sino como reflejo de la angustia y de la impotencia de muchas personas de buena voluntad que desean firmemente la paz. Porque -piensan- los estallidos bélicos y de violencia están fuera de nuestro alcance como ciudadanos normales. Y, por otra parte, pretender una cultura de paz, educar para la paz, sería formar seres inermes para una sociedad utópica que no es la nuestra, desvalidos ante la magnitud de la violencia que van a encontrar y, por tanto, no preparados para la dura competitividad real de la vida.

Es necesario tomar en serio estas dos legítimas preocupaciones, porque deciden sobre la validez 0 -en el mejor de los casos- ingenuidad de la propuesta de una cultura de paz. Frente a ellas, la cultura de paz y la educación para la paz parten de dos convicciones al menos como hipótesis de trabajo.

Primera, que no nos encontramos simplemente ante hechos excepcionales de violencia, sino ante una sociedad habituada a una cultura violenta. Los actos puntuales que saltan a la televisión, las graves confrontaciones bélicas, los casos para la sección de sucesos, no son sino la parte visible del iceberg de una sociedad que se ha vuelto violenta: prestemos atención al ámbito de los medios de comunicación, juventud, familia, escuela, empresa, fútbol, tráfico, política, religión, incluso del amor, y lo comprobaremos. La paz en el macroescenario mundial (más noticiable) es inseparable de la paz en el microentorno social (menos conocido). Los mecanismos que justifican la violencia a pequeña escala son los mismos que la justifican a gran escala. Desentrañando las causas de la violencia cotidiana que nos rodea nos preparamos para comprender la génesis de la violencia que nos espanta, y a 
la inversa. La cultura de paz no parte decero, sino que encuentra ya instalada una cultura de violencia. Por ello, una cultura de paz debe comenzar por desenmascarar los mecanismos por los que la sociedad se ha vuelto violenta, a uno y otro nivel de la existencia humana, para poder deducir y proponer como alternativa los caminos que llevan a una dinámica de paz.

La segunda hipótesis de trabajo es que toda sociedad es conflictiva y seguirá siéndolo. El conflicto es inherente a la convivencia humana. La cultura de la paz no busca eliminar los conflictos de la sociedad, sino encontrar las bases para resolver esos inevitables conflictos de manera humana y no violenta. Quien identificara paz con ausencia de conflictos, prepararía el camino a la imposición de las dictaduras o a la evasión de los pasotas.

Aceptadas estas dos premisas, la cultura de paz, antes que nada, debe solicitar una ayuda interdisciplinar para proyectar luz sobre los mecanismos por los que las personas, los grupos o la misma sociedad se vuelven violentos. En este breve trabajo con finalidad exclusivamente pedagógica consideraremos a los seres humanos en algunas de sus diversas dimensiones, advirtiendo que en la realidad son inseparables: biológica, personal, social y transcendente.

Dos observaciones. Primera, no hay que pensar tanto en las causas aparentes, próximas, visibles, de los hechos violentos, cuanto sobre todo en esos mecanismos sutiles, inconscientes, de justificación de la violencia, que hacen lógico y coherente su ejercicio a quienes la practican. Muchas veces son muy elementales y no les prestamos atención. Segunda, esos sutiles mecanismos de justificación afectan por igual a individuos y a colectivos, pueden mover tanto a las personas como a los pueblos, y por ello advertimos ya desde ahora que cuanto aquí se diga pretende tener validez en ambos casos.

\section{MECANISMOS DE J USTIFICACIÓN DE LA VIOLENCIA}

\subsection{Dimensión biológica}

Como punto de partida, la biología, y específicamente la etología que trata del comportamiento animal, soporta una pregunta clave ante la increíble violencia de la historia humana. ¿Serán los humanos violentos por 
naturaleza? Si la violencia fuera innata, heredada genéticamente, por trágico que fuera admitirlo, existiría al menos una explicación.

Los biólogos no parecen encontrar en su propia ciencia base suficiente para una respuesta afirmativa. La Declaración de Sevilla sobre la Violencia, promovida por la UNESCO y comunicada el 16 de mayo de 1986, recuerda en sus cinco proposiciones que no hay bases científicas para afirmar que la guerra es inevitable: Científicamente es incorrecto decir que la guerra o cualquier otro comportamiento violento está genéticamente programado en la naturaleza humana. Como conclusión proclama que la biología no condena a la humanidad a la guerra, al contrario, que la humanidad puede librarse de una visión pesimista anclada en la biología y, una vez recuperada su confianza, emprender las transformaciones necesarias de nuestras sociedades. En la reunión internacional celebrada durante el mes de septiembre de 1996 en Valencia sobre Biología y Sociología de la Violencia, tampoco fue posible a los científicos llegar a un acuerdo sobre cualquier determinación genética del comportamiento violento.

Los biólogos nos invitan, eso sí, a tomar en serio la agresividad natural que comparten los humanos con el mundo animal. Somos agresivos por naturaleza y ello constituye una riqueza vital en la supervivencia. Pero a la vez distinguen entre agresividad y violencia. La agresividad animal intraespecífica, a diferencia de la interespecífica, no es destructiva, sino constructiva. Porque existe también una solidaridad innata dotada de mecanismos de inhibición que impiden normalmente a la agresividad animal llegar a la violencia intraespecífica.

¿Por qué en los seres humanos la agresividad innata se convierte en violencia intraespecífica? Desde una perspectiva biológica se apunta sólo una sospecha: existe algún mecanismo humano motivado quizá por intereses diversos que degrada al otro a una especie inferior y se constituye a sí mismo en especie superior, rompiendo así la unidad de la especie humana. Así se justifica esa violencia como interespecífica. Antes de ejercer una violencia destructiva el ser humano ya ha degradado al otro -persona, grupo, pueblo, raza- hasta convertirlo en una especie inferior. Puede observarse históricamente cómo la des-humanización verbal del adversario suele preceder y crear las condiciones de legitimación de su eliminación física. Los nazis llamabas ratas y cerdos a los judíos. Los comunistas soviéticos llamaban hienas a los disidentes. Muchos terroristas denominan perros a los policías contra los que van a atentar. Los torturadores de cuerpos de

\section{RFS}


seguridad sólo ven ante ellos a bestias subversivas. A las protestas del embajador español superviviente tras el asalto a la Embajada española en Guatemala en el que murió tanta gente, se le respondió: No eran gente, eran indios.

Con motivo del asalto de militares peruanos en la madrugada del 20 de abril de 1997 a la embajada de Japón en Perú, tomada por el Movimiento revolucionario Tupac Amaru, se daban detalles de los 140 soldados y oficiales de elite que intervinieron. Escribía el corresponsal de El País (27.04.97): Todos altos y fuertes, felinos, rápidos de reflejos y salvajemente adiestrados. Verdaderas máquinas de matar, dice el analista Fernando Rospigliosi. Parte de su entrenamiento consiste en criar perros desde cachorros, después matarlos personalmente y comerse sus intestinos. Es una manera de des-humanizarlos.

¿Sería posible ejercer una violencia destructiva, si no existiese ese mecanismo intimo de justificación, no formulado, por el que hay seres inferiores, pueblos de segunda, razas medio humanas, clases que no dan la talla? ¿No es considerada a efectos políticos más valiosa la vida de un estadounidense que de un guatemalteco, de un español que de un subsahariano? Las armas de destrucción masiva se sirven tanto de la distancia física como de la distancia moral de quienes las manejan. Este mecanismo tipo de des-humanización sólo sospechado desde la biología, se verá confirmado por otras disciplinas.

\subsection{Dimensión psicológica}

La aportación de la psicología es contundente. La violencia se aprende y se acumula. La maduración de los seres humanos desde que nacen hasta que mueren se produce al mismo tiempo que van superando una serie de encrucijadas personales o grupales que giran alrededor de los núcleos amor y poder o valer. Todos, personas y pueblos, necesitamos sentirnos amados y experimentarnos valiosos o capaces de poder para alcanzar nuestros proyectos.

La percepción del desamor y de la impotencia, por una parte, y los sueños de ser el centro del amor y de omnipotencia o ausencia de límites, por otra, son situaciones patológicas que llevan a personas, grupos, clases o pueblos a chocar violentamente con la realidad, percibida en un caso como origen de la propia frustración y en otro caso como necesitada de salvación.

La psicología evolutiva y la psicología social nos muestran cómo este 
proceso de justificación de la violencia existe lo mismo en las personas que en los pueblos. La experiencia a que aludimos alrededor del amor y del poder, del desamor y de la impotencia puede darse en ambos casos. De ahí que pueda generar tanto la violencia individual como la violencia colectiva, proyectada contra uno mismo, en unos casos, o contra los demás, en la mayoría de ellos.

Se origina así ya desde el nivel psicológico una justificación de la violencia que a veces se confirmará desde una perspectiva religiosa: la violencia se reviste de un halo sacral porque destruye una sociedad mala (percibida como tal desde la frustración de la impotencia y del desamor) o porque la salva (necesidad sentida como señal de un destino manifiesto desde el protagonismo de la omnipotencia).

\subsection{Dimensión socioeconómica}

Los avances en los transportes y en las comunicaciones a lo largo de todo el siglo XX, pero sobre todo la espectacular revolución en las tecnologías de la comunicación en los últimos 20 años del milenio, ha producido un hecho hasta ahora inédito: la conciencia planetaria. Por primera vez en la historia podemos pensar todo el planeta en tiempo real: primero fue alcanzar el espacio terrestre (pensar todo el planeta) y luego muy recientemente fue el tiempo (verlo y percibirlo en tiempo real). Ni a comienzos del primer milenio, ni a comienzos del segundo milenio, la humanidad tenía conciencia de su existencia como tal, ni de sus confines, ni de su identidad, ni de su población. Muchos mundos coexistían, algunos perfectamente desconocidos entre si, otros lejanamente vislumbrados. Hoy todos pueden saber todo sobre todos en el mismo instante. Nos sentimos habitantes de un mismo universo interrelacionado e interdependiente. El siglo XX, como singular época de cambios, ha desembocado en un verdadero cambio de época.

Una posibilidad semejante constituye una oportunidad única: mirar el planeta con un nuevo espíritu de solidaridad y cooperación. Pero la gestión de esta primera mirada global que el ser humano puede lanzar sobre el mundo está siendo monopolizada por una nueva fase del capitalismo. Es la mirada mercantil que contempla al mundo único sólo como un mercado único, para después concluir que lo único, o al menos lo más importante, es el mercado. Nadie sensato puede negar al mercado ser un instrumento eficaz en la economía ni a la libertad de mercado haber alcanzado logros significativos en la regulación de una parte de las relaciones sociales. En cambio, una

\section{RFS}


mirada exclusivamente mercantil es capaz hoy de pensar el mundo a velocidad de vértigo, pero no de sentir pasión por la humanidad. Y esa humanidad dobla el milenio más insegura de lo que había esperado, con desconocidos miedos y angustias, insegura en su identidad y con un fuerte sentimiento de soledad, que genera frustraciones y a veces estalla en todo tipo de violencias.

El monopolio de la lógica neoliberal, sin otros correctivos externos e incapaz por sí misma de una solidaridad planetaria, convierte 0 al menos permite un mundo único pero antagónico e injusto, y por ello portador de gérmenes de violencia a diversos niveles. Voy a llamar la atención sólo sobre tres de ellos.

A. La creación de una industria de armamento recibía su justificación normalmente de la necesidad de garantizar la defensa nacional, por lo que en parte estaba constituida en muchos países por empresas públicas, aunque una vez en marcha intentara conseguir nuevos beneficios a través de la exportación. La privatización de estas industrias, la concentración empresarial y su transferencia en muchas ocasiones a capital transnacional (el caso más reciente ha sido Santa Bárbara en España), ha hecho que se homologue con el resto del mercado en sus objetivos de obtener exclusivamente los máximos beneficios. La industria y comercio de armas, que acostumbra a ignorar las normas de conducta recomendadas por Naciones Unidas e incluso por la Unión Europea, es un grave problema para una cultura de paz y tiene una incidencia directa en el mapa mundial de la violencia.

No pensemos sólo en las armas pesadas o en las estratégicas. Hay 500 millones de armas ligeras en el mundo, que son las utilizadas en la mayor parte de los conflictos armados locales con una increíble crueldad. Otros pequeños artefactos como las minas antipersonas, de las que hay 110 millones enterradas esperando cada día a su víctima, son difíciles de erradicar y su desactivación constituye un negocio para las mismas empresas que las han fabricado. Los medios de comunicación nos ofrecen cada día noticias de matanzas en escuelas, familias, bares o calles del país líder en la defensa de la democracia en el mundo, Estados Unidos, donde su Presidente ha recibido poderes para llevar a cabo guerras espectaculares en el Golfo o en Kósovo, pero ha carecido hasta ahora de la capacidad para controlar la libre circulación de armas de fuego en su propio país, debido al enorme peso del consorcio de fabricantes.

B. Pero, además, el mismo modelo económico que ha conducido a un crecimiento de la riqueza sin precedentes en la historia, produce $y / 0$ 
consiente situaciones inhumanas de desequilibrio en el reparto de los bienes materiales y culturales. La globalización tiene ganadores y perdedores. Y, como afirma el reconocido investigador noruego Johan Galtung, llamar paz a una situación en la que imperan la pobreza, la represión y la alienación es una parodia del concepto de paz. La pobreza es hoy la mayor violencia estructural y fuente de desesperación existente. El desarrollo integral es simplemente otro nombre de la paz.

Durante 1995, Año Internacional para la Erradicación de la Pobreza, se instaló un Reloj de la Pobreza en el vestíbulo principal del edificio de la ONU en Nueva York. Cada minuto 47 personas, cada día 70.000, cada año 25 millones, engrosaban entonces inexorablemente el número de los pobres de la Tierra.

El Programa de Naciones Unidas para el Desarrollo (PNUD) viene publicando desde 1990 su Informe sobre el Desarrollo Humano, que constituye una buena radiografía de la salud del mundo en el desarrollo humano y por lo tanto un eficaz diagnóstico sobre el futuro de la paz. Los últimos Informes 1997, 1998 y 1999 ponen de relieve respectivamente la sangrante desigualdad existente en cuanto a ingresos, al consumo y al acceso a las nuevas tecnologías. Todavía 1.300 millones de personas viven en pobreza absoluta, cuando los expertos del PNUD confiesan que tenemos los medios técnicos para erradicarla hoy, como en otro tiempo se erradicó ya la esclavitud o el colonialismo, y que lo único que falta es la voluntad política.

Pero por ahora Carmen Sarmiento, excepcional profesional dotada de una fina sensibilidad, no pudo titular su nueva serie en TVE "Ios explotados" o "Ios marginados", sino simplemente "Los excluidos". Eduardo Galeano apostilla con su habitual agudeza: La pobreza puede merecer lástima, pero ya no produce indignación; hay pobres por ley de juego o por fatalidad del destino. Hasta hace 20 ó 30 años, la pobreza era fruto de la injusticia. Lo denunciaba la izquierda, lo admitía el centro, rara vez lo negaba la derecha. Mucho han cambiado las cosas en poco tiempo: ahora la pobreza es el justo castigo que la ineficacia merece, 0 un modo de expresión del orden natural de las cosas. El código moral ya no condena la injusticia, sino el fracaso.

C. Cada modelo económico está sustentado en un modelo cultural. La Ilamada cultura de la satisfacción vincula la felicidad al consumo de ciertos bienes materiales. Es natural entonces que se origine una desesperada carrera de competitividad para satisfacer ciertas expectativas, que quienes la promueven con una eficaz publicidad saben no están al alcance de todos.

\section{RFS}


Se crea así un estado de frustración tanto en las personas como en los pueblos que ven inalcanzable la posesión de bienes y a ello achacan su fracaso. Eduardo Galeano expresa de nuevo con agudeza esta explosiva paradoja: El norte del mundo dicta órdenes de consumo cada vez más imperiosas, dirigidas al sur y al este, para multiplicar los consumidores, pero en mucha mayor medida multiplica a los delincuentes. Convida a todos al banquete, pero a la mayoría les cierra las puertas en las narices. La invitación al consumo es una invitación al delito. La sociedad de consumo emite alegres mensajes de muerte.

Pero no menos frustrados quedan quienes, personas o pueblos, van alcanzando cotas mayores de consumo en una permanente competición, sin que por eso queden saciados sus deseos y consigan una definitiva felicidad. Porque del modelo quedan sorprendentemente marginados los valores más profundos de la existencia: lealtad, amistad, generosidad, gratuidad, solidaridad, belleza, naturaleza, religiosidad, 0 , lo que es peor, éstos se gestionan también en orden a su rentabilidad. No es desarrollo sustentable aquel que no puede sustentar la existencia en su sentido más hondo. La frustración personal o colectiva, sea por carencia o por vacío, se desliza fácilmentehacia la violencia en el ámbito familiar, social y político.

Pero el modelo cultural difusamente extendido por la primacía de la economía incluye dos criterios de actuación no promulgados pero vigentes: la eficacia y la inmediatez. Lo que se pretende o se encarga debe ser conseguido con eficacia, lo que a veces equivale a decir a cualquier precio. Todo vale. Todo es instrumentalizado y subordinado a conseguir la meta propuesta. Incluso las vidas humanas. El triunfo en un mercado competitivo lo exige. Por otra parte, no admite plazos largos, los resultados deben ser inmediatos, se acentúa el vértigo de la prisa, madre de los radicalismos, puesto que todo lo humano tiene su propio ritmo para no ser violentado y exige capacidad de apuesta a la larga. Con estos dos criterios se va enraizando en la sociedad el convencimiento de que la capacidad de ejercer una cierta violencia pertenece al talante de los triunfadores, porque otros medios pacíficos no son tan eficaces ni rápidos.

Esta cultura no formulada se extiende a otros ámbitos de la realidad social. La economía ha adquirido prioridad sobre la política y le traslada con frecuencia sus comportamientos, en detrimento de la democracia como moral y de los mismos derechos humanos. El homo politicus hoy día parece carecer de principios éticos propios y claros, y participa de una extraña 
mezcla del homo oeconomicus (eficacia empresarial a toda costa y prisa) y del homo religiosus (sacralización del propio proyecto como salvador de los ciudadanos o de los pueblos y por tanto sobre ellos).

Este esquema económico-religioso se hace más patente en las relaciones internacionales, en las que priman los intereses y apenas están presentes otros criterios éticos que permitirían un mejor funcionamiento de los organismos internacionales. Los supremos intereses nacionales son la justificación suficiente de acciones, que pueden llegar a la eliminación de personas y pueblos. La sacralización de la patria, de la etnia, del grupo, y la eficacia a cualquier precio son, al parecer, criterios suficientemente válidos.

\subsection{Dimensión de la comunicación}

Economía y comunicación son los dos fenómenos que dominan el escenario social de la humanidad en el cambio de milenio. Ya hemos hablado de los enormes avances en las tecnologías de la comunicación sólo en las dos últimas décadas. Por eso no faltan quienes caracterizan a nuestro tiempo como la era de la comunicación y a nuestro mundo como la sociedad de la información. Los avances científicos y técnicos en principio son positivos y abren nuevas posibilidades a la humanidad. Pero como to do lo humano son ambiguos. Por eso también hay que analizar de qué manera repercuten las insospechadas posibilidades en la comunicación e información en la cultura de paz y de diálogo.

\section{A. Concentración del flujo informativo y cambios en la estructura de la información}

Antes de analizar los contenidos, nos encontramos ya con tres rasgos estructurales que caracterizan hoy el mundo de los medios: la increíble concentración del flujo informativo a través de fusiones empresariales multimedia que aúnan intereses financieros, políticos y profesionales; el predominio de la imagen sobre la palabra gracias a la posibilidad de trasmitirla en tiempo real; y la sobreinformación a que se ven sometidos los ciudadanos especialmente con la llegada de Internet.

Sólo me es posible exponer estos cambios en la estructura de la información de masas en breves enunciados:

- Lo que no tiene imagen no existe. Hay muchos hechos estimulantes o

\section{RFS}


muchos otros conflictos en el mundo pero sólo existen aquellos que alcanzan imagen en los medios. Se ha llegado a la sustitución de la palabra por la imagen.

- Podemos ver la historia en marcha. Informar no es narrar o explicar un acontecimiento, sino hacernos asistir a él. El mediador desaparece: ustedes mismos se informan. La historia transcurre delante de mí como si yo fuera un espectador y no un actor coprotagonista de ella. El espectáculo predomina sobre la noticia.

- Ver es igual a comprender. Si veo lo que pasa, entiendo lo que pasa. Esta semantización (reducción de un tema muy complejo a algo muy simple, una imagen 0 un eslogan) no favorece el análisis, el razonamiento, el diálogo, la matización, la maduración de opiniones. Ver no es comprender y sin embargo toda una parte de la eficacia de la moderna concepción de la información está basada en esta ecuación.

- Creación de emociones. Las imágenes estimulan los mecanismos afectivos y emotivos de la personalidad más que la capacidad de razonamiento. Los pueblos en momentos claves se movilizan menos por razones que por emociones. Por eso una imagen (ha crecido la importancia de la telegenia), puede hoy suscitar más fácilmente sentimientos amistosos u hostiles, la consideración del amigo o del enemigo. Apelaciones visuales o semánticas a la religión, la nación, la raza, pueden desatar auténticas e imparables movilizaciones muy débilmente argumentadas. Lo emocional predomina sobre lo racional.

- Las mentiras de la guerra. Con ello las posibilidades de manipulación han crecido. La mentira en la información ya no es un hecho marginal a la guerra, sino forma parte de la misma estrategia de manera que llega a ser difícil establecer la frontera entre la verdad y la mentira. La Guerra del Golfo fue un claro exponente de ello. Los medios configuran la acción violenta como una acción siempre proyectada desde los otros hacia nosotros, nunca a la inversa. Nuestros ciudadanos son víctimas de la violencia, nunca responsables inmediatos o mediatos. No se genera debate y compromiso, sino disposición a aceptar decisiones interesadas ya previamente tomadas por quien hace llegar la información.

- La sobreinformación es desinformación. Se dice que la sobreinformación es la censura de los países democráticos y puede también asfixiar la libertad. Ante la sobreinformación bruta (no jerarquizada como en el 
periodismo serio) cada uno bucea solamente en busca de lo que le interesa, con lo cual crece enormemente en los conocimientos de lo que le es propio (especialización) y decrece en la posibilidad de ampliar sus conocimientos que era propia de la tradición periodística. Es el usuario quien construye su realidad, contemplada a menudo en una soledad bien lejana del debate o de la tertulia.

\section{B. Los Medios de Comunicación Social (MCS) ¿causa o reflejo de la violencia?}

Pasando de los cambios en la estructura de la información a sus contenidos, en la cultura de paz se suscita la eterna cuestión: ¿los MCS son simplemente reflejo de una violencia existente en la sociedad o su causa? Parece evidente que la violencia existe y tiene sus raíces fuera de los MCS. Sin embargo:

- Los medios de comunicación, que permiten hoy abarcar todo el planeta en tiempo real, producen una concentración artificial de los hechos violentos, cuya densidad no se da en la realidad. Existe la ley implícita de que lo noticiable no es la vida normal y pacífica sino la violencia. La historia parece consistir en una concatenación de hechos violentos, más que en el esfuerzo paciente de muchas generaciones de ciudadanos. Por otra parte, la concentración de imágenes o noticias duras suele producir, por instinto de conservación, bien un encallecimiento de las mentes que impide cualquier reacción responsable, bien la huída a un estado de fascinación. Aunque rechazemos la violencia real, fascina su supuesta consideración estética.

- La velocidad vertiginosa con que opera la información descontextualiza los hechos. Esto puede producir efectos contraproducentes. La repulsa que produce la violencia, sin un análisis sereno de sus causas y de su contexto, puede llevar a un reforzamiento del orden establecido quizá necesitado de profundas transformaciones. La alternativa se plantea con enorme simplismo: o la delincuencia o el orden existente. Eso está ocurriendo ahora con el fenómeno en crecimiento de la emigración y toda su compleja problemática.

- Se ha hablado a veces de la función de catarsis o purificación que ejerce la violencia contemplada por ejemplo en los telefilms. Para ello sería necesario que los espectadores tuvieran capacidad de distanciarse y de 
verlos como un juego, pero en realidad muchos, sobre todo jóvenes, se sumergen en lo que contemplan y encuentran allí modelos de identificación. Por desgracia hay siemprequien ejerce la violencia en virtud de los más nobles sentimientos adquiriendo la categoría de héroe. El profesor Certeras, de la Universidad de Washington, apunta que: Cuando los niños ven la televisión adquieren la impresión de que la violencia es algo común, cotidiano, efectivo y carismático. Los niños no imitan simplemente lo que ven, sino que almacenan esa información, en este caso agresiva, y la pueden reproducir en cualquier otro momento de su vida.

\subsection{Dimensión transcendente}

Finalmente, incluso en el carácter trascendente de los seres humanos, en el ámbito de lo religioso, pueden encontrarse mecanismos que justifican la violencia. Corruptio optimi pessima. Es conveniente distinguir tres tipos de relación entre la violencia y lo religioso.

A. La violencia sacralizada. Antropológicamente la violencia que mata o destruye tiene una pretensión sacral. El mecanismo sacralizador es el convencimiento de que es ejercida contra el mal (que no merece existir, es infrahumano), o de que es ejercida por el bien (salvador, más-que-humano, que sabe lo que conviene a todos, que redime a toda costa). Esta justificación sacral tiene una raíz maniquea que ha servido para legitimar desde la pena de muerte hasta la guerra nuclear (la realidad se divide entre el Bien absoluto y el Mal absoluto), que los creyentes no pueden compartir. La mentira es que intrahistóricamente no existen ni el Bien ni el Mal absolutos. La fe cristiana confiesa por un lado que todos tenemos al guna parte o responsabilidad en el mal (Pablo en Romanos afirma que todos somos pecadores) y, por otra parte, todos somos por gracia hijos de Dios y hermanos. Nadie puede arrogarse ser el Bien sin mezcla de mal, ni eliminar a otros como el Mal que no contenga su propio y original bien. Además, la muerte en cruz de Jesús, inocente, ha puesto fin al mito del chivo expiatorio (tema al que ha dedicado un profundo y discutido análisis René Girard).

La fe cristiana aporta además otro dato: la felicidad humana reside no en la posesión (de bienes o de seres humanos como bienes) sino en la comunión (con Dios, con los seres humanos y con la creación entera inseparablemente). Por eso no tiene sentido resolver los conflictos venciendo a otros (con su eliminación física o moral). Una creencia madura invita a con- 
vencer, vencer-con-los-otros, para no destruir incluso la propia condición de felicidad. Erich Fromm afirma: La finalidad de una estrategia de paz debe ser evitar la derrota del oponente. La única estrategia de paz consiste en el reconocimiento de los intereses recíprocos. Me atrevo a pensar que encontramos una secularización de este principio religioso en la doctrina de la seguridad compartida que propuso Olof Palme: no puedo estar nunca seguro, si mi seguridad no busca e incluye a la vez la seguridad del otro. Esta sencilla tesis tiene la más amplia aplicación en todos los ámbitos de la vida personal y social, nacional e internacional.

B. La violencia que brota de la misma actitud religiosa. Se trata de la dirección inversa: el deslizamiento de lo religioso hacia la violencia. ¿Cómo? El ámbito de lo religioso nos afecta más vital y emocionalmente que otros porque tiene que ver con el sentido de nuestra vida y de nuestra muerte. $Y$ sin embargo nada se presta menos a la objetivación. La persona religiosa percibe que ha de distinguir entre el Absoluto, Dios, misterio insondable al que se confía, y los conceptos, palabras o mediaciones institucionales en que se expresa. Laíndole absoluta de aquello a que el creyente apunta descalifica cualquier pretensión de poseer el misterio desbordante desde la limitación humana. Cuando no es así y se otorga a las mediaciones humanas el mismo carácter absoluto que al misterio trascendente a que apuntan, se puede genera el fanatismo y la consiguiente violencia moral e incluso física.

D. La manipulación de lo religioso desde fuera de su ámbito. Más frecuente todavía que la violencia originada por patología del mismo hecho religioso, es la apelación a la religión con carácter movilizador desde fuera de su propio y específico ámbito. Se suscita lo religioso para defender políticas, culturas, instituciones de poder, naciones o etnias particulares en el curso de conflictos que tienen otro origen. Al filo del milenio no apelan a lo religioso tanto los estados (las guerras de religión fueron superadas por la secularización del estado democrático y el pluralismo religioso), cuanto las identidades (que se sienten amenazadas por el debilitamiento de los estados y por el fenómeno de la globalización). La cobertura religiosa de estos conflictos los agudiza a la vez que dificulta su diagnóstico y su terapia.

\section{ECOLOGÍA DE LA PAZ}

Puede parecer que estas consideraciones han sido demasiado negativas. No se olvide su modesta pretensión. Pasar página de una cultura de violencia a una cultura de paz exigía conocer algunos de los diversos y sutiles

\section{RFS}


mecanismos de justificación de la violencia que hunden sus raíces en algunas dimensiones de la existencia humana. Si es correcto el negativo conseguido, es posible con cierta facilidad conseguir un positivo adecuado y encontrar las pistas pedagógicas para construir una cultura de paz.

Renuncio por ello a formular en positivo "qué hacer", pero al menos quisiera recordar "dónde estar" para poder hacer algo. No se puede desarroIlar la vida humana en nuestro planeta si se deteriora su ecosistema. Si se me permite la extrapolación, existe sólo un medio ambiente en el que resulta posible la cultura, el cultivo de la paz. Ese ecosistema está amenazado, si no dañado, por una difusa cultura muy extendida en amplios sectores. Por eso una ecología de la paz necesita urgentemente recuperar:

- El sujeto responsable, frente al mero espectador paralizado de la historia.

- La preocupación por lo público y comunitario, frente al refugio en la privacidad.

- Los valores compartidos, frente al puro pragmatismo o al vacío ético.

- La imaginación creativa, frente a la nostalgia infecunda del pasado o al desánimo.

- La capacidad en mantener las metas, aun cuando vivamos tiempos de perplejidad en cuanto a los medios.

- La lucidez incansable en el trabajo de análisis y búsqueda de mediaciones, frente al simplismo que cree basta la buena voluntad.

- La ternura y el humor que ama lo humano y a la vez conoce sus limitaciones, frente a la tensión y la angustia militantes.

- La humildad y modestia, frente al prometeísmo de las ideologías totales.

En todo caso no olvidemos, como avisa Burde, que no hay nadie más necio que aquel que no hace nada porque sólo puede hacer un poco. 